\title{
Elizandra Souza: escrita periférica em diálogo transatlântico
} Sílvia Regina Lorenso Castro ${ }^{1}$

No Brasil, as narrativas sobre a periferia transitam entre a semântica da violência e a da carência. ${ }^{2}$ Não raro, palavras como "periferia," "morro" ou "favela" suscitam um imaginário marcado por disputas, tráfico de drogas, "gangues", tiroteios e assassinatos. Em 1998, tais imagens foram exploradas e exportadas para o mundo com o filme Cidade de Deus, adaptado do romance homônimo de Paulo Lins. Ambas as representações sequer consideram a clivagem de raça, focando apenas na perspectiva de classe, e pouco problematizam, por exemplo, as várias dimensões de gênero.

Escrever, na perspectiva do morador da periferia, era coisa de gente branca, de classe média/alta, dos bairros nobres, da universidade. Eles é que tinham o saber e a voz para falar, para representar conceitos e realidades. Essa ideia que liga a habilidade da escrita a uma certa espacialidade segregada na cidade, a um certo fenótipo humano, a uma certa condição de classe foi discutida na pesquisa de Regina Dalcastagnè, cujo corpus contou com 258 romances publicados por três das principais editoras brasileiras em um período de 15 anos (1990-2004). Os dados do estudo confirmam que o romance brasileiro é escrito majoritariamente por homens. E mais: os resultados apontam ainda que não apenas o escritor mas a personagem do romance brasileiro contemporâneo também é representativa de um perfil social específico: é majoritariamente branca, heterossexual e rica ou de classe média (Dalcastagnè, 2005, p. 28-39).

\footnotetext{
${ }^{1}$ Doutora em língua e literatura luso-brasileira, professora e diretora de Middlebury School no Brasil, Niterói, RJ, Brasil. E-mail: slorenso@middlebury.edu

${ }^{2}$ Este artigo é uma versão modificada de um dos capítulos da minha tese de doutorado, realizado na Universidade do Texas, Austin. Agradeço à Capes e ao Carolina Postdoctoral Program For Faculty Diversity, da Universidade da Carolina do Norte, Chapel Hill, que me possibilitaram dedicação exclusiva, respectivamente, na fase inicial e final da pesquisa. Uma parte deste artigo foi apresentada como comunicação oral na conferência da Latin American Studies Association (Lasa), que aconteceu em Chicago, em maio de 2014. Agradeço aos diferentes interlocutores que, em diferentes momentos, ofereceram valiosos insights, especialmente Arturo Arias, Lucimar Dias, Cristiano Rodrigues, Nirlene Nepomuceno, Jossianna Arroyo e Niyi Afolabi.
} 
É nesse contexto que a vida e a obra da escritora Elizandra de Souza tornam-se uma espécie de lente de acesso, permitindo-nos ler a literatura e a periferia brasileiras partindo de outra perspectiva: uma perspectiva negra, feminista, jovem, urbana, conectada com as inovações tecnológicas da vida moderna, relacionada a um agir local e um pensar global a partir de referências afrodiaspóricas, em consonância com as teorias negras feministas e com o pensamento descolonial latino-americano. Vida e obra de Elizandra estão inseridas em um diálogo mais amplo sobre a atual geração de jovens escritores e escritoras da periferia de São Paulo, adeptos da cultura hip-hop e responsáveis pela produção literária e pelos saraus em bares nos bairros periféricos da cidade.

Este trabalho é parte desse diálogo e tem como objetivo ler sua produção literária e cultural como um processo de reivindicação e afirmação feminista negra que aponta direções inovadoras no universo da produção cultural e literária da periferia paulista. Parto do pressuposto de que esse processo se caracteriza pelo que Leda Martins chamou de tempo espiralar, ou seja "um movimento ancestral, fonte de inspiração, [que] matiza as curvas de uma temporalidade espiralada, na qual os eventos de uma cronologia linear estão em processo de uma perene transformação" (Martins, 2000, p. 79). Esse movimento de reivindicação e afirmação espiralar pode também ser visto como um sampler, uma mixagem de diferentes sonoridades e textualidades que, ao acontecer simultaneamente, formam outra coisa.

Assim, argumento que Elizandra parte de uma formação identitária espiralar/sampleada, que atravessa e expande as páginas do livro em sua materialidade impressa, para construir uma ponte entre música (hiphop), literatura (Punga e Águas da cabaça) e tecnologia (Rádio Comunitária Heliópolis). Ao fazê-lo, Elizandra instaura uma presença política que rasura e contesta a construção social que vê o morador da periferia como um sujeito modalizado pela falta.

Na mesma direção de Nelson Maca (fundador e organizador do Sarau Bem Black, em Salvador), argumento ainda que não é possível entender a obra de Elizandra nem a atual periferia brasileira se não for levada em consideração uma multiplicidade de elementos, tais como: os mecanismos alternativos de comunicação comunitária, a cultura hip-hop e os saraus. Meu argumento final é de que seu livro Águas da cabaça (Souza, 2012a) desafia uma centralidade masculina que tem se tornado predominante 
nas narrativas da e sobre a periferia, ao mesmo tempo que aponta uma aliança transnacional com outras escritoras da diáspora africana.

A leitura da vida e da obra de Elizandra cruza dinâmicas de gênero, raça, classe, espacialidade urbana e geração, inserindo-se no contexto das teorias negras feministas, especialmente, no que Patricia Hill Collins chama de interseccionalidade das opressões (Collins, 1990) na luta contra as matrizes de dominação. Outro referencial relevante é o conceito de conhecimento situado (Collins, 1990), pois a posição de Elizandra - jovem negra da periferia com formação em comunicação social - oferece aporte único para navegar na cidade como escritora e produtora cultural, reescrevendo a própria história.

Linda Smith, em Decolonizing methodology (Smith, 1999), discute as maneiras pelas quais os indígenas maoris têm articulado um projeto de descolonização ao desafiar a visão ocidental de produção do conhecimento. Segundo a autora, o projeto indígena maori parte do pressuposto de que a teoria e as ações de resistência precisam ser conjugadas na busca da autonomia e da sobrevivência dos povos, de suas culturas e linguagens. Esse projeto do qual fala Smith sugere uma intervenção social baseada na interface entre diferentes procedimentos, a saber: o uso da escrita para reescrever a história, a reformulação de nomes e conceitos, a celebração do processo, a preservação da oralidade como arquivo coletivo, a partilha, a demarcação de gênero, a visão de futuro, entre outros.

Tal perspectiva também pode ser ativada para ler o que vem sendo construído por escritores e produtores culturais das periferias no Brasil. Na prática, a produção literária, os programas de rádio, a realização de saraus semanais, entre outras atividades, estão transformando a agenda do cotidiano dessas comunidades e, por extensão, remapeando a produção cultural e literária na cidade.

\section{Quem é Elizandra}

De família do interior baiano, Elizandra Batista de Souza nasce em três de julho de 1983, na periferia da Zona Sul de São Paulo. Aos 2 anos de idade, a família retorna para o Nordeste. No início da adolescência, nova migração faz com que ela retorne à capital paulista. Aos 13, em 1996, ela se depara com duas periferias: uma marcada por intensa violência e outra por um tipo de cultura que representa muitos dos seus 
anseios de jovem periférica vivendo um bombardeio de representações negativas na mídia (Silva, 2011). Em meados dos anos 1990, o movimento hip-hop emerge nas periferias - grupos de rap como Racionais MC's e DMN cantam letras de protesto contra a situação da população negra e periférica, além da presença marcante da dupla Thaíde e DJ Hum. Grupos de break dance tomam a cena urbana no centro da capital paulista, num espetáculo de corpos em movimento; os graffiti colorem as paredes das comunidades; bailes black se espalham pela cidade. É nesse caldeirão cultural que a adolescente vai se encontrar e fortalecer sua raiz identitária negra.

Do ponto de vista do seu background educacional, Elizandra faz parte de uma geração de jovens da periferia contemplados com bolsa de estudo no ensino superior privado por meio do Programa Universidade para Todos (Prouni). Esse fato possibilita sua entrada, e posterior graduação, no curso de comunicação social, com habilitação em jornalismo, pela Universidade Mackenzie. Atualmente, Elizandra conjuga suas atividades de escrita com o trabalho como editora e jornalista responsável pela edição da Agenda Cultural da Periferia.

\section{Hip-Hop e a geração fanzine}

No final dos anos 1980 e no início dos 1990, antes da proliferação da internet, além das rádios comunitárias, ${ }^{3}$ era comum ver jovens associados ao hip-hop ou admiradores do gênero escrevendo letras de rap ou produzindo fanzines. De fato, era através de fanzines que circulavam informações sobre os grupos de rap, fotos, entrevistas, agendas de eventos etc. Elizandra integra o Coletivo Mjiba em Ação ${ }^{4}$ e cria o fanzine homônimo, que durou de 2001 a 2005. "Mjiba" é uma palavra do léxico da língua shona, do Zimbábue, e quer dizer "jovem mulher revolucionária". Essa foi a forma encontrada por Elizandra para pagar tributo ancestral às mjibas, "as mulheres guerrilheiras que lutaram pela independência de seu país - Zimbábue” (Souza, 2012).

\footnotetext{
${ }^{3}$ Sobre a história de uma das mais famosas rádios comunitárias do Brasil, indico o filme baseado na história da Rádio Favela FM, em Belo Horizonte: "Uma Onda no Ar" (DVD), filme de Helvécio Ratton, 2002.

${ }^{4}$ Grupo de mulheres negras da região do Grajaú, em São Paulo, responsável pelo evento anual que comemora o Dia da Mulher Negra, em 25 de julho.
} 
De forma geral, os estudos sobre mulher e hip-hop abordam a forma sexista/misógina das letras de rap ou o papel secundário das mulheres como esposas, namoradas ou backing vocal dos cantores de rap. Se, por um lado, essa perspectiva aponta para as tensões de gênero no interior de uma cultura que se pretende revolucionária, por outro, ela perde de vista outras maneiras pelas quais as mulheres vêm participando e construindo a cultura hip-hop como protagonistas.

Elizandra, por exemplo, depara-se com o hip-hop através das músicas do grupo Racionais $\mathrm{MC}^{\prime}$ s, vê sua condição social representada no discurso cantado na voz potente de Mano Brown, mas não sente o mesmo em relação às discussões de gênero. Por isso, ela encontra na produção de um fanzine - o Mjiba - uma linha de atuação a partir da sua habilidade com a escrita.

Além de construir um espaço de articulação da própria voz, Elizandra constrói também o caminho da sua inserção e colaboração na cultura hip-hop, de modo que ela logo percebe a importância daquele espaço como plataforma inicial de divulgação dos primeiros passos como poeta. Para muitos jovens da época, o fanzine era considerado "coisa de mulher", o que torna intrigante a constatação de que a entrada da mulher no hip-hop se dá exatamente pelo que a Zulu Nation ${ }^{5}$ define como o quinto elemento do hip-hop: o conhecimento através da escrita. Esse quinto elemento expande e complementa os demais: rap (música), DJ (sampler), break (dança) e graffiti (artes visuais).

Ao discutir a participação negra feminina na cultura hip-hop, Gwendolyn D. Pough desenvolve o conceito de bringing wreck, que seria o momento em que o discurso da mulher negra perturba os discursos masculinos que dominam o hip-hop, entra na esfera pública e, de alguma forma, influencia ou impacta a percepção nacional, mesmo que de maneira passageira (Pough, 2004, p. 76). Na década de 2000, a internet substituiu a elaboração de fanzines, os quais propiciaram visibilidade e pautaram temas importantes para o público feminino do hip-hop até então. Mas não seria arriscado afirmar que a prática da escrita pode ser sentida hoje na produção de jovens escritoras como Elizandra. A escrita em fanzines representou a primeira vez em que jovens negras das periferias experimentaram o estatuto de autoras, protagonistas das próprias narrativas, trazendo outra

\footnotetext{
${ }^{5}$ Zulu Nation é uma organização não governamental que surgiu no bairro Bronxs, em Nova Iorque, criada pelo DJ Afrika Bambaata, considerado o precursor do hip-hop.
} 
voz para dentro do hip-hop brasileiro, para a cidade de São Paulo e, por extensão, para o país. A partir daí, os próximos passos de Elizandra foram entrar para a faculdade de comunicação e cursar jornalismo, participar do Sarau da Cooperifa e de antologias poéticas, publicar dois livros, produzir a Agenda Cultural da Periferia e apresentar um programa na rádio comunitária Heliópolis, também na Zona Sul de São Paulo.

\section{Poema ao hip-hop: "Eterno amor"}

Em 2006, Elizandra publica nos Cadernos Negros o poema Eterno amor, no qual declara sua paixão pelo hip-hop.

Nunca acreditei em amor verdadeiro

Via muitos magoados por esse traiçoeiro

De repente só precisei te olhar

Era o tal do amor à primeira vista a pousar

Nos apaixonamos e prometemos nunca mais separar

As pessoas sempre falaram muito mal de você

Mas eu sempre soube o quanto a sinceridade fazia parte do seu ser

Já estávamos juntos há quase nove anos

Nunca o esquecerei

Pois foi o ser de mais encanto

Quantas luas vimos juntos?

Você no meu coração plantou a paz (Souza, 2006, p. 13).

O poema faz parte da primeira leva de produção de Elizandra e aborda sua relação com o hip-hop, a qual se dá por duas fases. A primeira fica evidente que se trata de uma relação de atração que se transforma em "amor à primeira vista". Ao voltar a São Paulo no início da adolescência, a escritora encontra a cultura hip-hop, e nasce daí a construção de uma enunciação que vai demarcar o impacto desse encontro. O poema evidencia ainda a má reputação que o gênero enfrentou na chegada ao Brasil, quando foi associado à "música de bandido", leia-se "música de preto" ("as pessoas sempre falaram muito mal de você", diz o poema supracitado). Trata-se de uma construção de versos simples, com rimas finais e utilização padrão da linguagem, sem uso de gírias - elemento bastante presente nas letras de rap. Essa primeira fase marca a fase de impacto do encontro com uma cultura que a representa.

A segunda fase, no entanto, marca outro momento do impacto que a cultura hip-hop teve no sujeito da enunciação. 


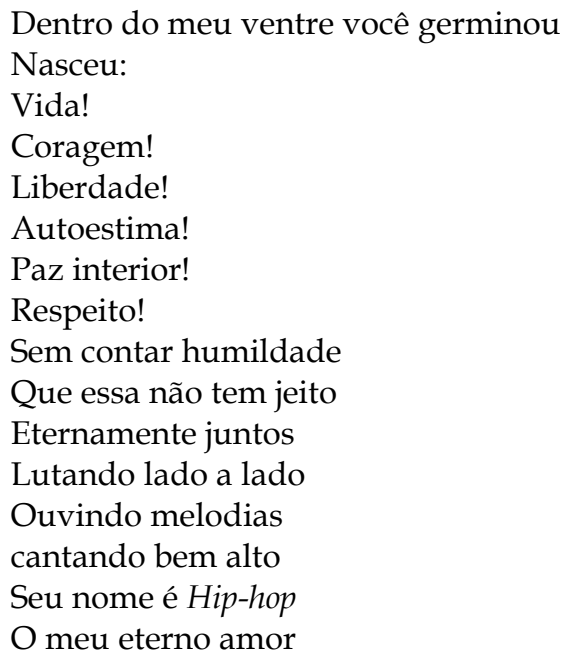

No poema, o hip-hop não foi apenas um encontro casual seguido de amor romântico. A imagem criada é de algo que germina, transforma, que gera outra vida, outra configuração. Há uma transformação que se faz presente pela simbologia da fecundação: "dentro do meu ventre você germinou". Essa fecundação é o processo que leva a uma agência política. No verso "lutando lado a lado", a voz poética proclama uma parceria com o hip-hop no sentido de luta. E luta aqui é entendida como batalha discursiva de instauração de uma contranarrativa para a reescrita de uma nova história. Essa perspectiva pode ser comprovada quando Elizandra afirma que o hip-hop foi o canal de negociação da sua consciência racial, foi espaço para sua reconfiguração identitária e política: “Sim, o hip-hop me fez ser preta para me enxergar como pessoa. O hip-hop me deu autoestima de enegrecer a cada dia, trançar ou dredar os cabelos e não me sentir ridícula com os olhares que recebo na rua" (Souza, 2010).

\section{Agenda Cultural da Periferia e Rádio Heliópolis}

Em 2007, toda a efervescência, o boom da produção cultural periférica e a invisibilidade ou limitada oferta de divulgação dessa produção no meio mainstream levaram a organização não governamental Ação Educativa a produzir a Agenda Cultural da Periferia, com o objetivo de divulgar a produção dos artistas entre a própria comunidade e, assim, fomentar o intercâmbio entre eles. A agenda tem periodicidade mensal e tiragem 
entre 6 e 10 mil exemplares. No sumário do primeiro volume, que tem formato de brochura, leem-se os seguintes tópicos: hip-hop, rodas de samba, graffiti, literatura periférica, outras cenas e a periferia por dentro. Nos anos seguintes, percebe-se a inclusão das categorias teatro, cinema e formação cultural, o que aponta para uma diversidade cultural para todos os gostos e para a complexificação do universo cultural da periferia.

Em 2009, foi lançado um website como arquivo da agenda e, em 2011, a equipe investiu na divulgação também nas redes sociais e em rádios comunitárias. Elizandra coordena um programa semanal de uma hora na rádio Heliópolis FM, que vai ao ar toda terça-feira, de $16 \mathrm{~h}$ às $17 \mathrm{~h}$. O programa divulga o conteúdo da agenda, realiza entrevistas ao vivo com artistas que figuram na versão impressa, toca músicas e interage com os ouvintes. Tanto a versão impressa quanto a versão na rádio incorporam uma significativa presença da literatura associada aos saraus.

A agenda contribui, assim, para formar e ampliar o público consumidor da produção cultural da periferia. A estratégia de utilizar a letra impressa, o universo on-line e as ondas do rádio e não apenas confiar nas brechas apresentadas pelos meios mainstream pode ser vista como uma pedagogia descolonial, conforme elabora Catherine Walsh. Para ela, pedagogias descoloniais são aquelas produzidas no contexto de luta, marginalização e resistência, funcionando no sentido de possibilitar outras maneiras de ser, estar, pensar, saber, sentir, existir e conviver (Walsh, 2013). Para o morador da periferia, a página escrita não é o único meio de acesso à informação.

Através das ondas sonoras, Elizandra sabe que pode ter acesso a um número muito maior de pessoas na comunidade, aquelas que talvez não leiam, mas escutam a rádio Heliópolis e podem despertar o interesse para as atividades divulgadas pelas diferentes versões da agenda. Ela vai construindo seu lugar próprio na cidade utilizando não apenas a letra impressa, mas também as ondas do rádio ou, como diz CarcamoHuechante, voicing differences (Carcamo-Huechante e Legani, 2010, p. 33).

Pode-se inferir, portanto, que, ao utilizar o rádio como um grande veículo de divulgação e articulação de outra voz, Elizandra segue a mesma estratégia utilizada por outros sujeitos subalternos latino-americanos - os indígenas na Argentina e no Chile e as populações urbanas na Nigéria -, isto é, a rádio local como possibilidade prática e simbólica de conexão comunitária (p. 41). Nesse sentido, ela dialoga com o que defende Collins, 
ou seja, o empoderamento individual é muito importante, mas apenas a ação coletiva pode efetivamente gerar uma duradoura transformação política, social e econômica (Collins, 1990, p. 237).

\section{Elizandra, a poeta: o processo significa}

Entre 2005 e 2012, Elizandra divulgou seu trabalho em antologias: nos Cadernos Negros números 29, 30, 32, 33 e 34 (2006-2011), bem como na Antologia do Sarau Elo da Corrente e na Coletânea Negrafias, para citar algumas. Além dessas colaborações, ela publicou um livro de poesia em parceria com o escritor Akins Kinté (Souza e Kinté, 2007).

Somente em 2012 foi publicado seu primeiro livro individual (Souza, 2012a). Punga ${ }^{6}$ saiu pela Edições Toró, tendo a coordenação editorial partilhada entre ela e quatro homens, o poeta e editor Allan da Rosa, o diagramador Mateus Subverso, o designer gráfico Marcos ZX e o ilustrador e grafiteiro Bylla, todos seus amigos. A composição da equipe de produção do livro é um dado importante para ser pensado em relação ao processo de produção de seu segundo livro e primeiro de autoria individual, o qual contou com a participação de seis mulheres negras (totalizando sete com a autora), numa construção simbólica e de reforço político instaurado pelas sete mulheres negras produtoras e controladoras da própria enunciação poética.

Punga tem nove sessões representando fases diferentes no universo feminino, e cada uma reúne três poemas (com exceção de uma delas, que tem quatro): "MenstruAção", "Feto", "Menina pretinha", "Mistério", "Guerrilha cotidiana", "A luz da lua", "Sofrimento de guerreira", "Meu único dia de mulher" e "Realeza". Cada sessão tem um significado para a poeta, mas, das nove, uma interessa particularmente para o argumento deste trabalho: "MenstruAção." Grafada propositalmente com a letra " $A$ " maiúscula, a palavra menstruação desdobra-se em duas: menstrua e ação. Na página ao lado, na qual se encontra o poema, há uma garota negra, de cabelos com dread, sentada ao vaso sanitário, lendo um livro cujo título diz: História preta.

Além de "MenstruAção", há outro poema que representa o tom afirmativo da mensagem poética - "Escavação" -, de modo que tomarei "MenstruAção" e "Escavação" para abordar o que parece ser a linha

\footnotetext{
${ }^{6}$ Ressalto que não abordarei a parte do livro que trata dos poemas do poeta Akins Kinté, visto que, no momento, meu interesse recai sobre o tom poético de Elizandra.
} 
geral do projeto poético-político instaurado em Punga e que irá ser retomado e ampliado em Águas da cabaça.

Assim, abrindo a coletânea de poemas em Punga, o poema "MenstruAção" projeta um tom ativista, de orientação, de comando, endereçado às mulheres, utilizando-se da forma verbal do imperativo: "sangre/expele do teu corpo/junte/todo o amargor/sangre outra vez/sinta com intensidade essa cólica/mas sangre outra/sangre essa hipocrisia/junte todas as dores expelidas/retire da calcinha/jogue fora". O poema é um chamado para que as mulheres partam de sua própria condição feminina, fazendo disso uma ação coletiva contra o que as oprime. Essa mensagem é mais bem compreendida se colocada em relação ao poema que segue na próxima página, "Escavação" (p. 7): “Escavo-me todo dia/tentando me encontrar/Ora acho ouro/ora acho trapo/Nesse embaraço/acho diamante bruto/mas procuro o lapidado/Cristais, pedras/preciosas/acontece.../Mas sempre me deparo/com escombros, caquinhos/resíduos do que já foi.../nessa procura de mim mesma/ora me encontro/ora me perco".

Em "MenstruAção", a linguagem recorre à enumeração de atos conectados com a fluidez do sangue, a agonia, a dor e a necessidade de aguentar esse momento passageiro de sofrimento. No poema "Escavação", nota-se a metáfora das minas de extração de minerais para complementar essa ideia de busca de si, de uma transformação que acontece de maneira processual e, por vezes, até contraditória. Pensando na produção imagética que acompanha as páginas do livro (a cabaça e o ritual de purificação nas águas doces, a garota lendo um livro de história, o cabelo dread), pode-se inferir que se trata de um discurso de afirmação de identidade negra. A simbologia da mineração ou escavação remete à recorrente tentativa instaurada pela voz discursiva de conhecer a essência de algo que não é possível ver por fora. Dito de outra forma, ao chamar a sociedade brasileira de hipócrita em "MenstruAção", essa voz poética o faz com firmeza e convicção, questionando o modelo de relações raciais no Brasil, que relega às mulheres negras a base da discriminação racial, de gênero e de classe.

Nesse sentido, a busca de "pedras preciosas" e "diamante bruto" é metáfora desse projeto em busca de uma identidade negra perdida, de uma dimensão africana e afro-brasileira que faz parte da experiência dos negros brasileiros. Experiência essa entendida como algo que se aprende, pois a busca de referenciais sobre as rotas e 
raízes africanas é um constante projeto de "tornar-se" (tornar-se negra, tornar-se afro-brasileira), nos moldes de Neuza Santos Sousa (1983). A identidade racial a qual a poeta aponta em sua obra não é dada biologicamente, mas se faz como um construto social, como algo que se pode cavar até encontrar.

Pode-se inferir, portanto, que Punga marca uma afirmação de gênero e racial que vai se tornar o principal tema da poética de Elizandra. E ela o faz, ao colocar em discurso um fenômeno próprio da semântica feminina - a menstruação -, que se constitui de restos ou sobras do que não foi fecundado, mas também podendo representar algo velho que se transforma, através do processo de expulsão, para dar lugar a outro ciclo de vida. A menstruação aqui é tomada não como um fenômeno biológico, mas como um grito de libertação e poder. ${ }^{7}$ No plano do discurso, tem-se um ciclo iniciado por um rompimento com o passado opressor e com a ligação presente e futura de uma busca identitária, sendo a "escavação" um projeto de busca desse ser afrofeminino.

Assim, pressupõe-se que a poética de Elizandra instaura no enunciado e na enunciação a presença de uma mulher que se projeta negra e é assim que ela vai dialogar com a espacialidade urbana e periférica paulistana. É assim que ela se marcará como adepta dessa cultura afrodiaspórica tão relevante ao agenciamento político da juventude negra. E, ao fazê-lo, a poeta afirma que seu engajamento na história das relações raciais brasileiras se dará a partir da tomada da caneta, ou seja, da inscrição poética de suas percepções e atitudes, no espaço urbano periférico marcado por sua condição feminina.

\section{A gestação de Águas da cabaça}

O lançamento de Águas da cabaça (2012) marca uma fase mais madura e autônoma na produção poética de Elizandra. Para produzir o livro, ela convidou seis profissionais a quem foi confiada a tarefa de produzir todas as etapas de edição do livro: diagramação, ilustrações, prefácio e posfácio. Tudo sob seu controle e sua autonomia na decisão final. A essas profissionais Elizandra chamou de "parteiras." O livro,

\footnotetext{
${ }^{7}$ Sobre sangue, gênero e valores, ver Pegue McCracken (2003, p. 178).
} 
cuja produção durou quatro meses, conta com uma seleção de poemas já publicados anteriormente e outros inéditos.

Para Elizandra, o importante foi a "união dessas mulheres em torno de um projeto literário, é o protagonismo [...], fazer um livro bem feminino afro-brasileiro". E conclui: "Estou ansiosa para o lançamento para apresentar a criança para os amigos, leitores e leitoras que acompanham o meu trabalho" (Souza, 2012b). Essa afirmação implica dizer que Elizandra concebe seu primeiro livro como o processo gestacional de uma criança. E, nesse momento, evoca imagens ancestrais contidas na figuração das parteiras, mulheres habilidosas que realizam partos normais a partir da sabedoria prática e oral que receberam de suas antepassadas.

Essa seleção de mulheres negras para compor o livro enfatiza o que Collins chama de "dialética da opressão e do ativismo" (Collins, 1990, p. 12) e "política do empoderamento" (Collins, 1990, p. 237), ou seja, a matriz de dominação intercala a opressão da mulher com o ativismo e, desse lugar, viriam a produção intelectual das mulheres negras e seu consequente empoderamento político. Elizandra sentiu necessidade de controlar, também, o processo de edição do livro, inscrevendo sentido ao longo de todo o processo. Segundo Collins, a produção feminista negra implica ver o mundo como "um lugar dinâmico, no qual o objetivo não é meramente sobreviver ou se adequar. Em vez disso, ele se torna um local onde nos sentimos proprietárias e responsáveis" (Collins, 1990, p. 237, tradução nossa).

Observando a obra da Elizandra Souza, repara-se que sua poética se vale de uma sobreposição da história pessoal mesclada com a história do movimento negro, em especial da forma como mulheres negras têm se projetado na luta desse movimento social ao longo das décadas, especialmente a partir do final da década de 1970. A jovem negra da periferia, poeta, ativista cultural e jornalista faz parte de uma longa tradição de intelectuais negras feministas, aquelas que ampliam sua participação e intervenção na sociedade para produzir sonoridades e textualidades que elas deveriam ser capazes de ler e ouvir com mais frequência (Gonzalez, 1988b; Carneiro, 1993).

\section{Águas da cabaça}

Em Águas da cabaça, Elizandra engaja a ancestralidade africana da mesma forma como invoca o feminino. Nessa obra, a autora reinventa- 
se no processo metafórico de gestação, partindo da colaboração com as "parteiras". Não apenas o título mas também toda a obra gira em torno da iconicidade da "cabaça" e, ao fazê-lo, invoca a cultura africana tanto em seu elemento básico de utilidade (beber água) quanto em sua função de hibernação da semente. A semente, nesse caso, é a própria poesia-feto. A fecundação dessa mulher de ethos forte e guerreiro, invocado constantemente nessa obra, não passa pela via masculina. A poesia é o elemento fecundador desse corpo negro feminino. $\mathrm{Na}$ imagem da mulher grávida que abre as ilustrações do livro (Souza, 2012a, p. 12), encontra-se dentro da barriga uma cabaça e, dentro dela, o léxico "poesia". A cabaça é, portanto, o recobrimento que abriga a poesia-feto, que se transformará em ser vivo tão logo passe pelo "parto" desempenhado pelas amigas-parteiras, dando origem ao próprio livro, encerrando, assim, um ciclo de gestação para iniciar o próximo - de início da vida e da sociabilidade com o mundo. Pode-se inferir que a cabaça, no sentido empregado na obra de Elizandra Souza, projeta um labirinto poético cheio de ideias diversas que estão sendo gestadas coletivamente.

Portanto, a obra de Souza conecta-se com a proposta desse boom da literatura periférica mencionado anteriormente, no sentido de afirmar o papel transformador que a poesia vem exercendo na gestação de uma nova periferia, na conformação de uma nova cidade, aquela que não mais invisibiliza a voz e o corpo de sujeitos periféricos e suas produções discursivas, mas que os vê em sua potencialidade poética e multifacetada. Aqui, pode-se especular que a cabaça representaria a própria comunidade urbana periférica como um todo, e a poesia é o feto-fruto dessa nova gestação.

\section{Complexificando visões de gestação e maternidade}

Em Águas da cabaça, Elizandra utiliza a metáfora da gravidez (através da figura das parteiras) e da iconografia da gestação (na figura da cabaça), além de colocar em discurso, nos poemas, a temática da fertilidade. A metáfora da gestação associada à produção de um livro pode sugerir questionamentos em relação a um perfil de mulher que projeta o novo, que gesta ideias e promove transformações, mas não concebe a maternidade como o grande projeto de realização feminina. Tal questionamento pode ser facilmente equacionado se for 
entendido que não se trata, aqui, da projeção da gravidez em si, mas da defesa de uma centralidade coletiva e comunitária na ressignificação de universos particulares.

Se, por um lado, a atribuição da maternidade como característica intrínseca ao universo feminino tem sido fartamente criticada pelo movimento feminista numa perspectiva global, por outro, as teorias feministas negras entendem que, no contexto da interseccionalidade das opressões, a experiência negra atravessa e expande o conceito de gestação e maternidade biológica. Tal conceito existe vis-à-vis uma maternidade comunitária, política, em que o ato de cuidar é visto como um ato de solidariedade entre as mulheres negras, é uma rede dinâmica de interação que torna possível a vida negra cotidiana. Nesse sentido, mães de sangue ou mães de criação fortalecem uma perspectiva que centraliza a noção de comunidade no universo da família negra. Esse papel, obviamente, não existe isento de contradições (Collins, 1990, p. 133).

É relevante lembrar que a produção poética seguida de publicação só há bem pouco começou a fazer parte do universo da população periférica em geral, e da população feminina em particular. Assim, a associação metafórica tem mais a ver com o nascimento da poesia como um novo sujeito presente nessa comunidade-cabaça que apenas com a imagem da mulher que gera filhos. Ao invocar a figura das parteiras na composição de todo o processo do livro, a autora subverte a perspectiva individualista de produção literária. Ao fazê-lo, ela se inscreve na tradição feminista negra e descolonizadora que aposta no desenvolvimento de metodologias e pedagogias baseadas no poder comunitário como prática insurgente de resistir, (re)existir e (re)viver (Walsh, 2013).

Ao invocar um universo transatlântico de escritoras negras, Elizandra, simbolicamente, retoma a figura das parteiras para atribuir sentido à composição global da obra e compor uma espécie de mutirão poético. Esse "mutirão poético" está dividido em cinco fases, a saber: "Navego-me Eu-mulher"; "Não confunda com amor o sacrifício de si mesma"; "Não se vende o próprio sonho"; "O sonho é a verdade"; "Curvos são os movimentos do sol e da lua". Cada fase se inicia com a reverência a uma escritora africana ou da diáspora, uma mais velha, numa nítida recriação de licença poética, como se vê no ritual Ipadê, de saudação a Exu, no Candomblé, para abrir os trabalhos e abençoar a sequência da cerimônia. 


\section{Mutirão poético: as fases enunciativas de Águas da cabaça}

A primeira fase, "Navego-me Eu-mulher", começa com a invocação do poema "Fêmea-fênix", de Conceição Evaristo. Tematicamente, alguns dos demais poemas invocam: a ausência de algo perdido, a exemplo da saudade causada pela ausência do pai ("Ausência"); a veneração a Oxum ("Espelho de Iara"); a fertilidade como metáfora de geração de ideias reforçada na inscrição proposital da reversão da primeira letra de cada verso, formando a palavra fertilidade, o que sugere uma reinvenção desse conceito; a opressão de gênero que limita as várias potencialidades de a mulher ser o que bem quiser (nem presa ao arquétipo de santa nem ao de puta) ("Meio-termo"); a veneração do seu próprio Ori ("Raízes para fora da terra").

E ela segue elencando diversos temas e figuras, resumo de um amplo leque de seu processo de escrita criativa. Mas é o poema "Águas da cabaça" (Souza, 2012a, p. 32) que sintetiza os elementos-chave que permeiam o livro de maneira geral: a fertilidade e a possibilidade múltipla da cabaça.

Assim, ela se projeta nessa primeira fase da divisão dos cinco tempos da poética de Águas da Cabaça ("Navego-me-Eu-mulher"), revelando aspectos significativos da personalidade da voz poética: madura, consciente, espiritual, revolucionária, confiante e engajada.

\section{Não confunda com amor o sacrifício de si mesa}

Se, na primeira fase, a epígrafe foi tirada do poema de Conceição Evaristo, na segunda, intitulada "Não confunda com amor o sacrifício de si mesma", a autora se inspira na escritora zimbabuense J. Nozipe Maraire. Ao invocar Maraire, a partir de um trecho de seu livro Zanzele: uma carta para minha filha, ela institui uma nova persona na sua poética: uma mulher de individualidade forte, que experiencia relações e parcerias heterossexuais com o cuidado de quem se conhece e se sabe forte: "Você é uma menina forte, não se deixe vergar por ninguém. No mundo não existe um só homem que valha sua dignidade. Não confunda com amor o sacrifício de si mesma" (Souza, 2012a, p. 39). A voz poética não mais se coloca como aquela que está em busca de si mesma e de suas potencialidades espirituais, femininas, identitárias etc. Nessa fase, a narrativa se volta para o outro. É na relação com o outro que ela se 
constitui. Entendo que a colocação em discurso de um outro pode tanto ser entendida como o sujeito masculino quanto outras mulheres. Para os homens, a mensagem funciona como um aviso. Para as mulheres, como um alerta, um chamado de atenção. Nessa fase, o poema "Em legítima defesa" aponta para uma nova forma de enunciação.

Só estou avisando, vai mudar o placar...

Já estou vendo nos varais testículos dos homens,

Que não sabem se comportar

Lembra da cabeleira que mataram outro dia

$[\ldots]$

É mulher morta nos quatro cantos da cidade...

Só estou avisando, vai mudar o placar...

A manchete de amanhã terá uma mulher,

De cabeça erguida, dizendo:

Matei! E não me arrependo!

Quando o apresentador questioná-la,

Ela simplesmente retocará a maquiagem.

Não quer estar feia quando a câmera retornar

E focar em seus olhos, em seus lábios (Souza, 2012a, p. 48).

O poema insere-se na semântica do aviso. Trata-se de um sujeito feminino cansado dos abusos sofridos pelo companheiro. A voz feminina, sem reação às investidas passadas, decide tomar uma atitude mais proativa. Sua agência passa pela reação física (cortar os testículos), pela visibilidade na mídia não como a figura humilhada e vitimizada como em geral é mostrada, e também pela inscrição do feminino no corpo. Esse poema dialoga diretamente com o poema "Outra negra Fulô", de Oliveira Silveira, que parodia o poema "Essa nega Fulô", de Jorge de Lima (Castro, 2007). Em Jorge de Lima, a mucama é diversas vezes assaltada sexualmente pelo seu "sinhô". Um dia ela decide reagir e mata seu opressor, assume o ato como quem acaba de cortar as correntes que a oprime e se sente livre para celebrar com os seus.

\section{Não se vende o próprio sonho}

Nessa terceira fase, a autora evoca e homenageia, por meio de epígrafes, duas escritoras afro-brasileiras de gerações distintas (Souza, 2012a, p. 63 e 67). Na primeira, trata-se de Maria Tereza, autora de 
Negrices em flor (Tereza, 2007). Na segunda, Carolina Maria de Jesus é homenageada com um poema de Maria Teresa.

Nessa fase, dois poemas são emblemáticos de uma presença que conecta a luta negra nas Américas, a partir de um imaginário que critica a percepção de justiça e democracia racial no contexto do Estado-nação: "Revolta popular" e "Viva las mariposas".

\section{Revolta popular}

20 de novembro,

Feriado da Consciência Negra

Embrulhei o estômago na Praça da Sé

$[\ldots]$

Declamei poesias, comi berinjela no pão

Será que não era isso que Zumbi queria? (Souza, 2012a, p. 67)

O poema trata da luta de ressignificação do movimento negro brasileiro para questionar a data oficial de celebração da abolição da escravidão, passando do dia 13 de maio para o dia 20 de novembro, considerado pelo movimento negro brasileiro o Dia Nacional da Consciência Negra. É feriado em São Paulo. A voz poética se enuncia a partir do centro da cidade (Praça da Sé), local comumente escolhido por movimentos populares para a realização de manifestações. No poema, embrulhar o estômago e comer berinjela no pão é algo que remete ao sacrifício feito por militantes negros da periferia em suas ações de ativismo político, muitas vezes traduzidas na dificuldade de pagar pelo transporte coletivo da periferia até o centro para participar de tais manifestações, ou de pagar por uma alimentação de qualidade.

A pergunta "Será que não era isso que Zumbi queria?" é emblemática da condição socioeconômica que relega e mantém a população negra na base da desigualdade racial e social, o que distorce o projeto político simbolizado pela luta representada na figura do líder quilombola, Zumbi dos Palmares, homenageado em 20 de novembro. No entanto, a constatação de uma realidade dura que ainda persiste não apaga a convicção da intervenção política. Ao contrário, ela reforça o projeto de descolonização, nos termos de Linda Smith, conforme apontado anteriormente. Essa intervenção política adquire múltiplas facetas, representa uma celebração da sobrevivência e se fortalece no coletivo, conforme demostram os versos que se seguem: 
Cartazes, tambores e ira

Anarquismo e rebeldia

Fanzines, falares e fazeres

Vestes pretas e música contundente...

Movimento Punk é revolta popular da nossa gente.

Se o poema "Revolta popular" está circunscrito dentro de um Estado-nação, o poema "Viva las mariposas" adquire estatuto transatlântico, perceptível já no uso do artigo em espanhol "las", presente no título.

\section{Viva las mariposas}

As letras gritam,

Para que a história não seja esquecida

As ditaduras sejam derrubadas

E as mariposas continuem

A bater as asas em frente de lamparinas

Mulheres usem seus cabelos para

Esconderem os bilhetes e recados de mudanças

Subversão são as tranças, munição, que não

Desmancharam nossos sorrisos

Mulheres do mundo não se esqueçam delas

Viva las mariposas! (Souza, 2012a, p.75)

O poema refere-se às irmãs dominicanas conhecidas como las mirabal (Patricia Mirabal, Minerva Mirabal e Maria Teresa Mirabal). Elas eram conhecidas como las mariposas (em português, as borboletas) e foram brutalmente assassinadas em 25 de novembro de 1960 pelo ditador Rafael Leónidas Trujillo por se tornarem fervorosas opositoras das atrocidades cometidas em seu governo (1930-1961). Em homenagem às irmãs, a Organização das Nações Unidas (ONU) declarou a data de 25 de novembro como o Dia Internacional da Eliminação da Violência Contra a Mulher.

Ao produzir esse poema, Elizandra se coloca na posição de jovem mulher revolucionária, atenta às expressões de resistência feminista que, definitivamente, vão muito além de fronteiras nacionais. Nesse sentido, ela parece encampar a categoria de análise amefricanidade, da ativista e intelectual afro-brasileira Lélia Gonzalez (1988a), para dar conta da ampla experiência negra (e feminista) nas Américas. Essa experiência negra interroga e desafia o mito de um Estado-nação homogêneo, masculinizado e se apropria de referenciais inscritos fora 
dos padrões ocidentais, numa evidente apropriação da estética das tranças como subversão, conforme aparece nos versos finais: "subversão são as suas tranças, munição que não/desmancharam nossos sorriso."

Se somarmos a participação de Elizandra no coletivo Mjiba, seu poema "Viva las mariposas" e as diferentes citações de escritoras negras em diálogo no seu trabalho, pode-se concluir que a jovem Elizandra possui um conhecimento de fronteira - border thinking (Bejarano, 2005) -, uma vez que parte de uma intervenção local, mas age segundo contornos de um desenho global (Mignolo, 2012).

\section{Quarta fase: o sonho é verdade}

Nessa quarta fase, Elizandra toma emprestada uma passagem do livro Their eyes were watching God, de Zora Hurston. ${ }^{8}$ Nessa fase, são colocadas em discursos mulheres campesinas, faveladas ${ }^{9}$, mibas, zapatistas, africanas, indígenas e latinas, o que retoma o caráter espiralar e sampleado da poética de Elizandra, além de reforçar sua inserção no universo amefricano (Gonzalez, 1988a). A temática da fase atual perpassa ainda sobre a luta da jovem da periferia que entra na universidade privada e se vê diante da preocupação de pagar o boleto da mensalidade, em "Bancos da universidade" (p. 85); o legado do poeta e abolicionista Luis Gama, em "Gameleira” (p. 88), a África vista a partir da experiência da poeta, em "Maputo-Moçambique" (p. 90); e um legado ancestral, em "Chamado" (p. 97). No universo dessa fase, destaca-se o poema "Estribeiras do mundo" (p. 80):

Procuro escrever na minha poesia

A leveza das crianças nas costas das mães,

As mãos calejadas que não recebem

A beleza das flores...

As florestas que sangram leite.

\footnotetext{
${ }^{8} \mathrm{O}$ texto epigrafado de Zora Neale Houston foi tirado de Their eyes were watching God (Seus olhos viam Deus), publicado em 1937. O texto citado por Souza (2012a, p. 74) diz: "As mulheres esquecem tudo que não querem lembrar e lembram tudo que querem esquecer. $\mathrm{O}$ sonho é a verdade. Portanto, elas agem e fazem tudo de acordo com isso".

${ }^{9}$ O termo "favela" em São Paulo aparece pouco, sendo substituído pela categoria "periferia", o que talvez possa justificar a distância em relação ao centro da cidade. O termo "favela" é utilizado muito mais de maneira pejorativa por quem vê o local a partir de fora. Os moradores, não raro, referem-se a "comunidade", "morro", "periferia."
} 
A primeira estrofe remete a uma temática recorrente na obra poética de Elizandra: o perfil de mulher colocado em discurso carrega no corpo uma marca cultural de procedência africana. O verso "a leveza das crianças nas costas das mães" refere-se a uma prática comum no continente africano, especialmente em Moçambique - país visitado pela escritora -, onde as mulheres se utilizam dos tecidos chamados "capulanas" para carregar seus bebês nas costas enquanto realizam atividades diversas. Embora as capulanas sejam utilizadas para vestir mulheres de diferentes classes sociais do país, a prática de carregar bebês é mais recorrente no meio das mulheres pobres (Costa, 2013).

Como quero escrever

as lágrimas cristalinas das rochas, as Mjibas e as Zapatistas de mãos dadas

lutando de armas em punhos e de beleza libertária

No primeiro verso da primeira estrofe, a utilização do verbo "procurar" aponta para a intencionalidade da voz poética que busca registrar uma perspectiva balanceada entre a celebração da sobrevivência, através da beleza e da leveza, e aspectos da vida dura de mulheres pobres, representados na figura das mãos calejadas. $O$ primeiro verso da segunda estrofe, no entanto, inicia com a conjunção "como" e sugere o desejo da voz poética em registrar a luta das mulheres mjibas e das zapatistas. Embora não apresente pontuação, esse verso soa como uma exclamação.

Quero colocar Africanas, Indígenas, Latinas

na mesma luta por dignidade

porque a desigualdade é a mesma nas estribeiras do mundo...

A terceira estrofe demarca um tom mais contundente. A voz poética se coloca de maneira mais firme em sua posição e reforça o conceito de amefricanidade (Gonzalez, 1988a) ao enfatizar a necessidade de haver solidariedade entre mulheres africanas, indígenas e latinas.

A dança mais bonita

é o borbulhar de uma panela,

é o gingar das colheradas entre o prato e a boca as Mjibas, as Zapatistas, as Mirabals

voando com os pés firmes no chão

todas elas desatando nós. 
A última estrofe conclui com um tom bastante assertivo evocando a ação revolucionária de mulheres numa perspectiva transatlântica: mjibas, zapatistas e as irmãs Mirabal. Os versos que encerram o poema atribuem uma carga de esperança e positividade que vai da complexidade do ato revolucionário às demandas mais pontuais do cotidiano, tais como colocar comida na mesa e alimentar quem tem fome dentro de casa. O poema se encerra com a mensagem segundo a qual a grandiosidade dessas mulheres reside no fato de que elas se engajam numa luta com perspectivas globais e, ao mesmo tempo, sabem que a interseccionalidade das opressões também requer uma ação local para resolver as demandas específicas que não podem esperar: "voando com os pés firmes no chão/todas elas desatando nós".

\section{Curvos os movimentos do sol e da lua}

Paulina Chiziane ${ }^{10}$ é a escritora moçambicana trazida como referência no quinto e último movimento de Águas da cabaça, no qual há 32 poemas que tematizam elementos de afetividade romântica envolvendo um sol (figura que remete a um sujeito masculino) e uma lua (sugestivamente uma figura feminina). Uma leitura das estruturas semânticas aponta um conjunto de figuras que sugerem percepções muito timidamente eróticas, indo dos títulos ao conteúdo das estrofes: "mar doce", "estrelas que não apagam", "chegada", "boas águas", "pôr do sol”, "águas calmas", "admiração", " pássaros em pleno voo", "rosas brancas", "nostálgicas melodias", entre outras. Com algum esforço, percebe-se que, em "Nuances", a voz poética ousa se colocar de maneira menos eufemística:

Não são detalhes estes desejos de inteirança

Cravados nas minhas pernas entre suas costas

Narrativa minunciosa, essa que escrevo com suor

Deslizando entre salivadas palavras adocicadas

Nua ansiosamente inteira febril...

Quiromancia das minhas digitais no teu caminho...

\footnotetext{
10 "Mulher é linha curva. Curvos são os movimentos do sol e da lua. Curvo é o movimento da colher de pau na panela de barro. Curva é a posição de repouso. Nós mulheres somos um rio de curvas superficiais e profundas em cada palmo do corpo. As curvas mexem as coisas em círculo. Homem e mulher se unem numa só curva no serpentear dos caminhos" (Souza, 2012a, p. 99).
} 
O poema projeta uma carga de sugestão erótica menos contida e escondida em metáforas muito adocicadas. A voz poética expressa uma urgência em satisfazer os desejos "de inteirança", como se percebe no uso dos vocábulos com forte carga erótica: "suor", "nua", "ansiosamente", "febril".

É interessante notar que, no conjunto de sua obra, Elizandra projeta uma percepção global, com forte consciência revolucionária, desenvolve um pensamento crítico e vai muito além das fronteiras nacionais. Em outras palavras, seu ethos político é hiperbólico, forte, assertivo. No âmbito das relações afetivas e eróticas, no entanto, sua enunciação projeta um ethos muito eufemístico, partindo de um vocabulário que remete a certa timidez quase em desconforto. É como se o universo pessoal estivesse desassociado do político, o que vai na contramão dos estudos feministas negros, que afirmam que o pessoal é político (Cole e Guy-Sheftall, 2004). A poética de sugestão afetiva e erótica de Elizandra se aproxima muito de um perfil enunciativo encontrado em poemas eróticos da antologia Cadernos Negros, os quais também estão revestidos de um pudor semântico que gira entre a vergonha e a timidez de se colocar inteiramente no enunciado e na enunciação (Castro, 2007).

\section{Considerações finais}

Vida e obra de Elizandra mostram uma dinâmica espiralar/sampleada típica do universo periférico e da cultura hip-hop: ela intervém, conecta, escreve, representa, demarca posição, tem visão de futuro e reformula conceitos. Seu posicionamento a situa em um espaço contra-hegemônico na excludente cidade de São Paulo. Gênero, raça, classe, localização geográfica e geracional interseccionam as marcas da opressão, mas ela reescreve sua história. Uma história que começa na experiência da migração, na formação identitária como jovem negra e periférica, passa pelas estatísticas dos jovens negros que se tornam a primeira geração a alcançar o ensino universitário, insere-se no processo de produção simbólica de uma identidade de matriz africana, impulsionada em sua inserção nos coletivos de literatura negra e periférica, edita e publica seu próprio livro e dedica-se a promover a cultura da periferia, colaborando com uma rádio comunitária. Mais do que cíclica, a vida e a obra de Elizandra confundem-se e embaralham-se num mosaico espiralar no qual a periferia se torna centralidade e epistemologia. 
Ela faz da produção cultural e literária seu passaporte para a afirmação de uma agência política, com a sonoridade inquieta dos elementos do hip-hop.

No âmbito de uma enunciação poética que tematiza o político, sua produção é arrojada, criativa, manifesta-se numa percepção global sem deixar de pontuar as configurações locais. Sua compreensão da participação e da presença da mulher negra nos movimentos revolucionários em âmbito transatlântico coloca-a na privilegiada situação de seguidora do legado de Lélia Gonzalez, para quem a percepção feminina da diáspora era conceituada a partir da categoria "amefricana", entendida, atravessada e ampliada por Elizandra. No campo da colocação em discurso de uma voz afetiva e erótica, no entanto, a escritora utiliza-se do eufemismo como ferramenta discursiva e, com isso, projeta uma timidez semântica baseada na oposição "pessoal" versus "político." Sem dúvida, a jovem Elizandra Souza é uma das gratas surpresas surgidas no universo cultural e literário da periferia paulistana e o conjunto de sua vida e obra já é suficiente para colocá-la num patamar privilegiado no universo dos estudos da crítica literária, das teorias feministas negras e das discussões descolonizadas na America Latina e Caribe.

\section{Referências}

BEJARANO, Cintia (2005). ¿Qué onda? Urban youth culture and border identity. Tucson: University of Arizona Press.

CASTRO, Sílvia Regina Lorenso (2007). Corpo e erotismo em Cadernos negros: a reconstrução semiótica da liberdade. Dissertação (Mestrado em Semiótica e Linguística Geral) - Universidade de São Paulo, São Paulo.

CARCAMO-HUECHANTE, Luis E.; LEGNANI, Nicole Delia (2010). Voicing differences: indigenous and urban radio in Argentina, Chile, and Nigeria. In: SOMMER, Doris; SANÍN, Andrés. New directions for youth development. Danvers: Wiley Periodicals.

CARNEIRO, Sueli (2003). Mulheres em movimento. Estudos Avançados, São Paulo, v. 17, n. 49, p. 117-132, set./dez. Disponível em: <http://www.scielo.br/pdf/ea/v17n49/18400.pdf>. Acesso em: 26 jul. 2016.

COLE, Johnnetta B.; GUY-SHEFTALL, Beverly (2004). Gender talk: the struggle for women's equality in African American communities. Nova York: Ballantine Books.

COLLINS, Patricia Hills (1990). Black feminist thought: knowledge, consciousness, and the politics of empowerment. Boston: Unwin Hyman. 
COSTA, João Paulo (2013). As coloridas capulanas. Terras de Moçambique: recortes e impressões de um país. Maputo, 8 abr. Blogue. Disponível em: $<$ https://terrasdemozambique.wordpress.com/2013/04/08/as-coloridascapulanas/>. Acesso em: 27 jul. 2016.

DALCASTAGNE, Regina (2005). A personagem do romance brasileiro contemporâneo (1990-2004). Estudos de Literatura Brasileira Contemporânea, Brasília, n. 26, p. 13-71, jul./dez. Disponível em: <http://periodicos.unb.br/index.php/estudos/article/view/2123/1687>. Acesso em: 27 jul. 2016.

GONZALEZ, Lélia (1988a). A categoria político-cultural de amefricanidade. Revista Tempo Brasileiro, Rio de Janeiro, n. 92/93, p. 69-82, jan.jun.

GONZALEZ, Lélia (1988b). Por un feminismo afrolatinoamericano. Revista Isis International, Santiago, v. 9, p. 133-141, jun.

MARTINS, Leda Maria (2000). A oralitura da memória. In: FONSECA, Maria Nazareth Soares. Brasil afro-brasileiro. Belo Horizonte: Autêntica.

MCCRACKEN, Pegue (2003). The curse of eve, the wound of the hero: blood, gender, and medieval literature. Pennsylvania: University of Pennsylvania Press. (The Middle Ages Series).

MIGNOLO, Walter (2012). Local histories/global desings: coloniality, subaltern knowledge, and border thinking. Princeton: Princeton University Press.

POUGH. Gwendolyn D. (2004). Check it while i wreck it: black womanhood, hiphop culture, and the public sphere. Boston: Northeastern University Press.

RIBEIRO, Esmeralda; BARBOSA, Márcio (2006). Cadernos negros 29 (Poesia). São Paulo: Quilombhoje.

SILVA, José Carlos Gomes da (2011). Sounds of youth in the metropolis: the different routes of hip hop movement in the city of São Paulo. Vibrant. Virtual Brazilian. Anthropology, Brasília, v. 8, n. 1, p. 70-94, jan./jun. Disponível em: $<$ http:/ / www.scielo.br/scielo.php?pid=S1809-

43412011000100003\&script=sci_arttext>. Acesso em: 27 jul. 2016.

SMITH, Linda Tuhiwai (1999). Decolonizing methodology: research and indigenous people. Sidney: Zed Books.

SOUSA, Neuza Santos (1983). Tornar-se negro: ou as vicissitudes da identidade do negro brasileiro em ascensão social. Rio de Janeiro: Graal.

SOUZA, Elizandra (2006). Eterno amor. In: RIBEIRO, Esmeralda; BARBOSA, Marcio (Org.). Cadernos negros: poemas brasileiros. São Paulo: Quilombhoje, 2006, v. 29, p. 13. 
SOUZA, Elizandra (2010). Reportagem afetiva: meu déja vu. Blog Mjiba - Jovem mulher revolucionária. $30 \mathrm{dez}$. On-line. Disponível em: <http://mjiba.blogspot.com.br/2010/10/reportagem-afetiva-meu-dejavu.html>. Acesso em: 27 jul. 2016.

SOUZA, Elizandra (2012a). Águas da cabaça. São Paulo: Edição do Autor

SOUZA, Elizandra (2012b). Conheça um pouco da poetisa Elizandra Souza. Entrevista para o site Polifonia Periférica. 27 out. On-line. Disponível em $<$ http://www.polifoniaperiferica.com.br/2012/10/entrevista-conheca-umpouco-da-poetisa-elizandra-souza/>. Acesso em: 27 jul. 2016.

SOUZA, Elizandra; KINTÉ, Akins (2007). Punga. São Paulo: Toró.

TEREZA, Maria (2007). Negrices em flor. São Paulo: Toró.

WALSH, Catherine (2013). Pedagogías decoloniales: prácticas insurgentes de resistir, (re)existir y (re)vivir. Quito: Abya Yala.

Recebido em outubro de 2015.

Aprovado em janeiro de 2016.

\section{resumo/abstract/resumen}

\section{Elizandra Souza: escrita periférica em diálogo transatlântico}

Sílvia Regina Lorenso Castro

Neste artigo, discuto as conexões entre vida e obra de Elizandra Souza, escritora associada à produção literária da periferia de São Paulo, no âmbito das discussões teóricas sobre diáspora africana, pensamento negro feminista e pensamento descolonial latino-americano. Argumento que Elizandra parte de uma formação identitária espiralar/sampleada que atravessa e expande as páginas do livro na sua materialidade impressa para construir uma ponte entre música (hip-hop), literatura (Punga e Águas da cabaça) e tecnologia (Rádio Comunitária Heliópolis). Ao fazê-lo, Elizandra instaura uma presença política que rasura e contesta o imaginário sobre o morador da periferia como o sujeito modalizado pela falta. Defendo ainda que não é possível entender a obra de Elizandra, nem a atual periferia brasileira se não for levada em consideração uma multiplicidade de elementos, tais como: os mecanismos alternativos de comunicação comunitária, a cultura hip-hop e os saraus. Meu argumento final é de que seu livro Águas da cabaça desafia uma centralidade masculina que tem se tornado predominante nas 
narrativas da e sobre a periferia, ao mesmo tempo que aponta uma aliança transatlântica com outras escritoras da diáspora africana.

Palavras-chave: periferia, gênero, hip-hop, poesia, interseccionalidade.

\section{Elizandra Souza: peripheral writing in transatlantic dialogue}

Sílvia Regina Lorenso Castro

In this article, I discuss the connections between the life and work of Elizandra Souza, a writer associated with the literary production of the periphery of São Paulo. Her life and work are seen through the lens of black feminist thought and of Latin American decolonial thinking. I argue that Elizandra takes as her point of departure a spiraling and sampled identity formation that crosses and expands the materiality of the book's page to build a bridge between music, literature and technology. In so doing, Elizandra establishes a political presence that erases and challenges the perception about the inhabitant of the periphery as a subject defined by lack. I also argue that one might not fully capture the meaning of Elizandra's work, nor of Brazil's contemporary periphery if a multiplicity of elements is not taken into account, such as: alternative mechanisms for community communication, hip hop culture and the saraus. Finally, I argue that her book Águas da cabaça challenges the centrality of male discourse that has prevailed in peripheral narratives, while also articulating a transnational bond with other afro-diasporic women writers across the Atlantic.

Keywords: periphery, gender, hip hop, poetry, intersectionality.

\section{Elizandra Souza: escrita periférica en diálogo transatlántico}

Sílvia Regina Lorenso Castro

En este artículo, se discuten las conexiones entre la vida y la obra de Elizandra de Souza, escritora asociada con la producción literaria de la periferia de São Paulo, en el contexto de las discusiones teóricas sobre la diáspora africana, el pensamiento feminista negro y el pensamiento decolonial latinoamericano. Argumento que Elizandra toma como punto de partida una formación identitataria espiralada/sampleada que atraviesa y expande las páginas del libro en su materialidad impresa con la intención de construir un puente entre la música (hip hop), la literatura (Punga e Águas da cabaça) y la tecnología (la Radio Comunitaria de Heliópolis). De este modo, Elizandra establece una presencia política que borronea e impugna la percepción que la sociedad tiene respecto a los habitantes de la periferia como sujetos definidos por la falta. Sostengo además que no es posible entender la obra de Elizandra o la actual periferia brasileña si no se 
toman en cuenta una multiplicidad de elementos, tales como: los mecanismos alternativos de comunicación comunitaria, la cultura hip hop y los saraus. Mi argumento final es que su libro Águas da cabaça desafía una centralidad masculina que se ha tornado predominante en las narrativas sobre la periferia, mientras que señala una alianza transatlántica con otras escritoras de la diáspora africana.

Palabras clave: ciudad, género, hip hop, poesía, interseccionalidad. 